\title{
Nas fendas do regime escópico
}

\section{In the gaps of the scopic regime}

Lúcia Helena Fidelis Bahia ${ }^{1}$ 


\section{Resumo}

O presente artigo busca provocar rupturas plausíveis na corrente de pensamento proposta pelo regime escópico através do estudo das cegueiras no âmbito das artes, particularmente a cegueira funcional e seu espaço metafórico. Dessa forma, o texto evidencia autores como Georges Bataille e Jacques Lacan e artistas como Luiz Henrique Schwanke - e suas obras Paralelepípedo de luz (1990) e Cubo de luz (1991) - e Cildo Meireles com sua obra Espelho Cego (1970). Para isso, ele foi dividido basicamente em duas partes intituladas, respectivamente, de $A$ luz cegadora: de Bataille a Schwanke e $A$ experiência do espelho em Lacan e Cildo Meireles. Por fim, foram utilizados dois livros como base de sustentação da reflexão apresentada: Ojos Abatidos: la denigración de la visión en el pensamiento francés del siglo XX de Martin Jay e Blindness and Visual Culture: An Eyewitness Account de Georgina Kleege.

Palavras-chave: cegueira funcional; pensamento antiocularcêntrico; Luiz Henrique Schwanke; Cildo Meireles.

\section{Abstract}

The present article seeks to provoke plausible ruptures in the current of thought proposed by the scopic regime through the study of blindness in the arts, particularly functional blindness and its metaphorical space. Thus, this text puts in evidence authors such as Georges Bataille and Jacques Lacan, and artists such as Luiz Henrique Schwanke - and his works Light Paving Stone (1990) and Light Cube (1991) - and Cildo Meireles with his work Blind Mirror (1970). Finally, the article was basically divided in two parts titled respectively: The Blinding Light: from Bataille to Schwanke and The mirror experience in Lacan and Cildo Meireles. Ultimately, two books were used as a basis for the presented reflection: Downcast eyes: the denigration of vision in twentieth century French thought by Martin Jay and Blindness and Visual Culture: An Eyewitness Account by Georgina Kleege.

Keywords: functional blindness; antiocularcentric thought; Luiz Henrique Schwanke; Cildo Meireles.

ISSN: 2175-2346

1 apuslynx@gmail.com 
Uma possível ramificação da arte enquanto dimensão política encontra-se nas indagações dos regimes de verdade. Através da desconstrução desses regimes, é possível florescer múltiplas singularidades que engendram novos enunciados e suscitam saberes renovados. De acordo com Michel Foucault (2008, p. 98), em seu livro A Arqueologia do Saber, o enunciado "não é em si mesmo uma unidade, mas sim uma função que cruza um domínio de estruturas e de unidades possíveis e que faz com que apareçam, com conteúdos concretos, no tempo e no espaço." Um dos regimes de verdade mais influentes no pensamento ocidental e que carece ser abordado por meio de novos enunciados é o regime escópico, isto é, "aquele que privilegia o sentido da visão sobre os demais, particularmente por meio de modelos de percepção visual [...]" (BAHIA, 2016, p. 24-25), ocasionando a hierarquização dos sentidos tendo a visão como o mais nobre de todos. Certamente, uma ruptura viável à corrente de pensamento proposta pelo regime escópico pode surgir através do estudo das cegueiras no âmbito das artes ${ }^{1}$.

No prefácio do livro As palavras e as coisas, o leitor esbarra-se, após a confissão sobre o embaraço de ler o texto de Borges que cita a enciclopédia chinesa, em duas palavras, uma seguida da outra, sem desdobramentos consecutivos: atopia, afasia. Foucault anuncia, segundos antes, que o embaraço pode estar vinculado ao mal-estar daqueles cuja linguagem perdeu o comum do lugar e do nome. Do lugar partilhado constroem-se sulcos que avançam em direção a analogias como a derivada da palavra afasia que, além do sentido destinado ao livro, também tem um espaço reservado no universo da cegueira. Nele, há diversos tipos de cegueira que não são necessariamente vinculados ao dispositivo ocular, mas que podem gerar os mesmos sintomas observados na cegueira visual. São as denominadas cegueiras psíquicas e "acarretadas principalmente por lesões, doenças degenerativas, derrames ou outros artifícios que afetam a parte do cérebro responsável pela percepção visual, sua respectiva representação e também pela formação da linguagem" (BAHIA, 2016, p. 31). Dentre elas, existe uma conhecida como afasia ou agrafia que é utilizada para nomear o não reconhecimento de palavras.

Entretanto, o artigo concentra-se em outra categoria de cegueira psíquica que "permeia uma grande parcela de autores e artistas, gerando um distúrbio capaz de interceptar o espaço metafórico da percepção humana: a cegueira funcional" (BAHIA, 2016, p. 31 e 32). Ela emprega-se como aquilo que o indivíduo possui em excesso diante de seus olhos, porém não é capaz de captar em sua totalidade, apenas reter fragmentos dispersos que obliteram a visualidade, impedindo-o de ver com clareza. José Saramago, em seu livro Ensaio sobre a cegueira, aponta que o mundo vive em uma espécie de cegueira generalizada e alude à cegueira funcional no seguinte fragmento: "[...] Penso que não cegamos, penso que estamos cegos, cegos que veem, cegos que, vendo, não veem" (SARAMAGO, 1996, p. 310). Outro viés da cegueira funcional encontra-se presente nas diversas formas de leitura e suas respectivas interpretações, pois é plausível considerar que "por mais que se diga o que se vê, o que se vê não está jamais no que se diz" (FOUCAULT, 2001, p. 201-202).

\footnotetext{
1 É necessário esclarecer que há um pensamento, conhecido como antiocularcêntrico, que nasceu com o intuito de contestar as verdades ditadas pelo regime escópico através das inquietudes visuais manifestadas em "diferentes autores ao longo do tempo, particularmente nos franceses, como é o caso de Denis Diderot, Georges Bataille, Jean-Paul Sartre, Jaques Lacan, Maurice Blanchot e Jacques Derrida [...]" (BAHIA, 2016, p. 202), embora o artigo desenvolva uma crítica ao regime escópico sob a ótica de autores americanos.
} 
Com isso, o texto busca ressaltar artistas como Luiz Henrique Schwanke e Cildo Meireles que indagam sobre as inquietudes visuais de forma mais contundente, principalmente através de experiências-limite. Para isso, o texto foi dividido basicamente em duas partes: $A$ luz cegadora: de Bataille a Schwanke e A experiência do espelho em Lacan e Cildo Meireles. A primeira traz os questionamentos de Georges Bataille e dos artifícios presentes nas obras Paralelepípedo de luz (1990) e Cubo de luz (1991), e a última apresenta a recusa na crença da reciprocidade do olhar - desse olhar capaz de constituir a imagem de um indivíduo de acordo com o pensamento desenvolvido no estádio do espelho de Jacques Lacan, segundo a análise de Martin Jay sobre o autor - e a impossibilidade da construção da imagem, através obra Espelho Cego (1970) de Cildo Meireles. Como base de sustentação dessa percepção, explorar-se-ão alguns apontamentos e reflexões apontados nos livros Ojos Abatidos: la denigración de la visión en el pensamiento francés del siglo XX de Martin Jay e Blindness and Visual Culture: An Eyewitness Account de Georgina Kleege? ${ }^{2}$.

\section{Considerações introdutórias}

As cartas trocadas entre o filósofo cego Martin Milligan ${ }^{3}$ e o estudioso Bryan Magee - citadas no livro Sobre a cegueira (1995) e retomadas tanto por Oliver Sacks, em seu livro $O$ olhar da mente, quanto por Georgina Kleege, no texto Cegueira e Cultura Visual: o relato da testemunha ocular - tornaram-se um acontecimento relevante aos estudos sobre cegueira. Na carta, Milligan relatou que as pessoas videntes possuem acesso a experiências de um sentido - uma outra forma de conhecimento - que lhe é negado, ao mesmo tempo em que sustentou que os cegos congênitos podem ter experiências perceptivas ricas e variadas, mediadas pela linguagem e por imagens mentais de um tipo não visual como, por exemplo, auditivas ou olfativas (SACKS, 2010, p.209). Acrescentou ainda que a visão pode proporcionar algum prazer estético, por exemplo, a visualização de uma pintura, mas não o impede de conhecer o mundo visível a partir de descrições verbais. Além disso, segundo Kleege, Milligan acusou Magee de insinuar que a visão é um instrumento fundamental da existência humana, o qual diferencia pessoas videntes de não videntes, enquanto Magee, por sua vez, garantiu que sem a visão não é possível atingir um verdadeiro conhecimento do mundo visual. Magee, como descreveu a autora, também desqualificou Milligan como porta-voz dos cegos, pois acreditava que mesmo que ele tivesse perdido a visão ainda muito novo, poderia ter preservado um resquício de sua memória visual. Sem demora a afirmação de Magee foi contestada por um neurologista que comprovou que a perda da visão nos primeiros meses de vida tornaria o cérebro do indivíduo igual ao de um cego congênito. Para Bryan, o sentido da visão, para os que enxergam, é vivenciado como uma necessidade e um prazer progressivos, que permitem à sociedade tanto o espetáculo quanto o controle das formas de gerenciamento da visão.

2 A partir desse momento, o texto refere a um fragmento da minha dissertação intitulada Cegueira e Artes Visuais: paradoxos e implicações, defendida em agosto de 2016, sob a orientação da Profa. Dra. Rosângela Miranda Cherem, com pequenas alterações que possibilitam a fluidez do pensamento

3 Segundo Georgina Kleege (2013), Martin Milligan foi um ativista em favor das causas de cegos no Reino Unido e abordou discussões referentes às condições práticas e sociais que afetavam a vida das pessoas com deficiência visual. 
Magee afirma que quando as pessoas videntes são obrigadas a manter os olhos fechados por um curto período de tempo, isso induz a uma espécie de pânico. Para ilustrar seu objetivo, ele aponta que um método comum de maltratar prisioneiros é mantê-los vendados. [...] Certamente um prisioneiro cego, acostumado com a privação da visão, pode ainda ter sentimentos semelhantes de ansiedade e desorientação, devido ao perigo, explícito ou implícito [...]. (KLEEGE, 2013, p.453)

Na afirmação anterior é possível observar a privação da visão como algo ameaçador, mas é pertinente considerar que o excesso dela também pode acarretar as mesmas causas descritas - ansiedade, pânico, confusão. Na contemporaneidade, o dispositivo ocular tornou-se o meio através do qual as imagens definem, de acordo com o pensamento cultural vigente, os padrões. Esses padrões, tratando-se de algo simplesmente visível, podem provocar, a longo prazo, os mesmos sintomas daqueles que encontram-se desprovidos da visão - não propriamente do seu sentido, mas sim do reflexo de uma minoria não apontada nesses arquétipos. No entanto, não convencido com as premissas de Magee, Milligan evidenciou outra maneira de identificar padrões não vinculados apenas ao sentido da visão, apontando a possibilidade de sentir a presença de objetos grandes mesmo sem tocá-los, ou seja, uma forma de partilhar experiências perceptivas por meio da apreensão de mudanças atmosféricas experimentadas sinestesicamente, como uma das qualidades de uma pessoa cega.

De acordo com Georgina Kleege, considera-se que o obstáculo ao aprofundamento das qualidades de um cego esteja na dificuldade de localizar estatísticas sobre pessoas que nasceram totalmente cegas, pois a cegueira apenas é exposta quando a criança ou seus pais procuram os serviços para cegos, e isso tende a ocorrer somente quando a criança atinge a idade escolar. Ademais, pode-se concluir que houve um número maior de crianças que nasceram cegas no passado, uma vez que algumas das causas da cegueira infantil foram eliminadas pelas inovações médicas nos séculos XIX e XX. Porém, independente da época, as principais causas dessa patologia surgem no decorrer da vida e, em sua maioria, acarretam apenas uma cegueira parcial, onde alguns indivíduos conseguem conservar a capacidade de distinguir a luz da escuridão, enquanto outros podem continuar a perceber luz, cor, forma e movimento em determinado grau. Há ainda os que mantêm certa acuidade visual para ler impressões ou expressões faciais, e embora seja possível construir um padrão entre os casos, os cegos diferem bastante nas formas com que tratam, usam ou valorizam suas percepções (KLEEGE, 2013, p. 453). Apesar de Kleege indicar que muitos acreditam que apenas um cego pode falar com autoridade sobre cegueira ou apenas um vidente pode questionar o sentido da visão, o essencial é compreender que os estudos visuais contribuem para discussões sobre cegueira ao trazer "uma interrogação da oposição binária entre a cegueira e a visão" (KLEEGE, 2013, p. 454), tão apaixonadamente presente nas indagações antiocularcêntricas observadas a seguir.

\section{A luz cegadora: de Bataille a Schwanke}

É muito provável que as inquietudes visuais tenham obtido maior potência no período entre guerras. Um dos variados exemplos que as fomentou encontra-se no fato, descrito por Martin Jay, de que a invisibilidade do inimigo era revertida através do 
sentido auditivo quando se estava em terra, isto é, se não era possível ver o inimigo, ao menos era possível escutá-lo. Em contraposição a esse caso, aponta-se a perspectiva aérea do aviador, sustentando parte do regime escópico que, segundo Jay, ainda firmava-se a partir de associações como, por exemplo, entre o globo aerostático de Nadar e o aviador Antoine de Saint-Exupéry - pai do célebre Pequeno Príncipe -, aludindo à encarnação heróica do antigo mito de ĺcaro. Ao se pensar num diálogo entre os artifícios da perspectiva aérea e uma das histórias mais cativantes da modernidade, depara-se com vida e obra do aviador Saint-Exupéry indagando sobre a importância do visual. Apesar de ele ter contribuído na guerra com voos de reconhecimento aéreo para tentar impedir o avanço dos nazistas, em seus escritos desconfiava do sentido da visão, como pode ser observado na seguinte passagem de O Pequeno Príncipe: "o essencial é invisível aos olhos" (SAINT-EXUPÉRY, 2015, p. 101). Certamente sua literatura caminha em busca de um sentido para a vida e de uma essência humana, porém, é possível dizer que Saint-Exupéry não considerou a hegemonia de nenhum dos sentidos, assim como não depositou sua confiança no dispositivo ocular, como é perceptível no fragmento "os olhos são cegos/ é preciso ver com o coração" (SAINT-EXUPÉRY, 2015 , p. 113). Basta relembrar o primeiro contato do aviador com o pequeno príncipe, quando este lhe solicitou que desenhasse um carneiro; como o desenho semelhante à imagem do carneiro não agradou ao pequeno príncipe, o aviador desenhou, então, uma caixa e disse-lhe que o carneiro estava dentro, possibilitando uma reflexão sobre o que, realmente, a arte torna visível aos olhos dos espectadores. Portanto, o empobrecimento acarretado pelo excesso de visualidade era notório e influenciava diretamente a maioria dos artistas da época. Embora o cubismo não tenha sido analisado no texto,

[...] “a guerra cubista” também significou a queda prática da noção transcendental de uma perspectiva compartilhada, que já havia sido minada no plano teórico por Nietzsche. Com essa queda, produziu-se o retorno de todos os demônios aparentemente reprimidos pelo "processo de civilização", baseado em grande mediada no domínio do olhar desapaixonado.

Nenhuma figura no transcurso das décadas seguintes expressou o trauma e a êxtase dessa liberação com tanta força como Georges Bataille. Sem dúvida ninguém a vinculou de forma tão explícita com o destronamento do olho como ele. (JAY, 2007, p. 165)

O retorno dos demônios aparentemente reprimidos de Bataille pode ser remetido à série de fotografias de um suplício chinês, publicada apenas em 1961, anos após o seu primeiro contato com ela. As fotografias documentavam a história de um jovem chamado Fou Tchou Li, considerado culpado pelo assassinato do príncipe Ao Han Ouan e condenado ao esquartejamento vivo em cem pedaços, na China imperial. Na sequência das quatro fotografias, é possível ver pedaços de seu corpo arrancados, membros decepados, a pele em carne viva, o sangue escorrendo e, surpreendentemente, seu rosto fora de lugar, ausente daquela dor extrema (BORGES, 2001, n.p.). Com isso, pode-se perceber o interesse de Bataille em resgatar tanto experiências místicas do prazer pela morte quanto imagens características da Primeira Guerra que aludissem a experiências-limite. Uma dessas imagens é simbolizada pelo que se chamou luz cegadora, referência direta ao Sol cegador - aquele que ao mesmo tempo em que pos- 
sibilita a visibilidade é capaz de cegar -, e pode ser observada no percurso das obras Paralelepípedo de luz (1990) e Cubo de luz (1991), de Luiz Henrique Schwanke.

Essas obras são extensões da obsessão de Schwanke pela dicotomia claro/escuro e de seu fascínio pela luz. Segundo fragmentos de discursos do artista, desde que teve contato com indagações referentes à luz na história da arte, a fixação pelo claro/ escuro passou a fazer parte de sua obra e seu primeiro trabalho com luz foi intitulado de Apogeu claro-escuro pós Caravaggio. É necessário recordar que a dicotomia claro/ escuro também é observada em outros artistas, especialmente em Rembrandt, pintor que considerou a temática da cegueira em algumas de suas obras; e em Goethe, que atentou para essa oposição através da polaridade branco/preto conceituada, para ele, também como cor e não apenas presença/ausência de luz. Posteriormente, nas obras Paralelepípedo de luz (Figura 3) e Cubo de luz (Figura 4), através das quais ele retomou a apropriação deste elemento, buscou-a em sua quantidade máxima e em seu requinte de representação. Essa busca baseou-se, a partir de 1980, na expansão da luz "através de um grande facho que constituía a instalação montada na Galeria Sérgio Milliet, no Rio de Janeiro" (Vários autores, 2002, n.p.), composta, também, por apropriações de obras de artistas clássicos e barrocos (LAMAS, 2005, p. 181). A luz, então, para Schwanke, significava fonte de experiência sensível e estética (LAMAS, 2005, p. 191).
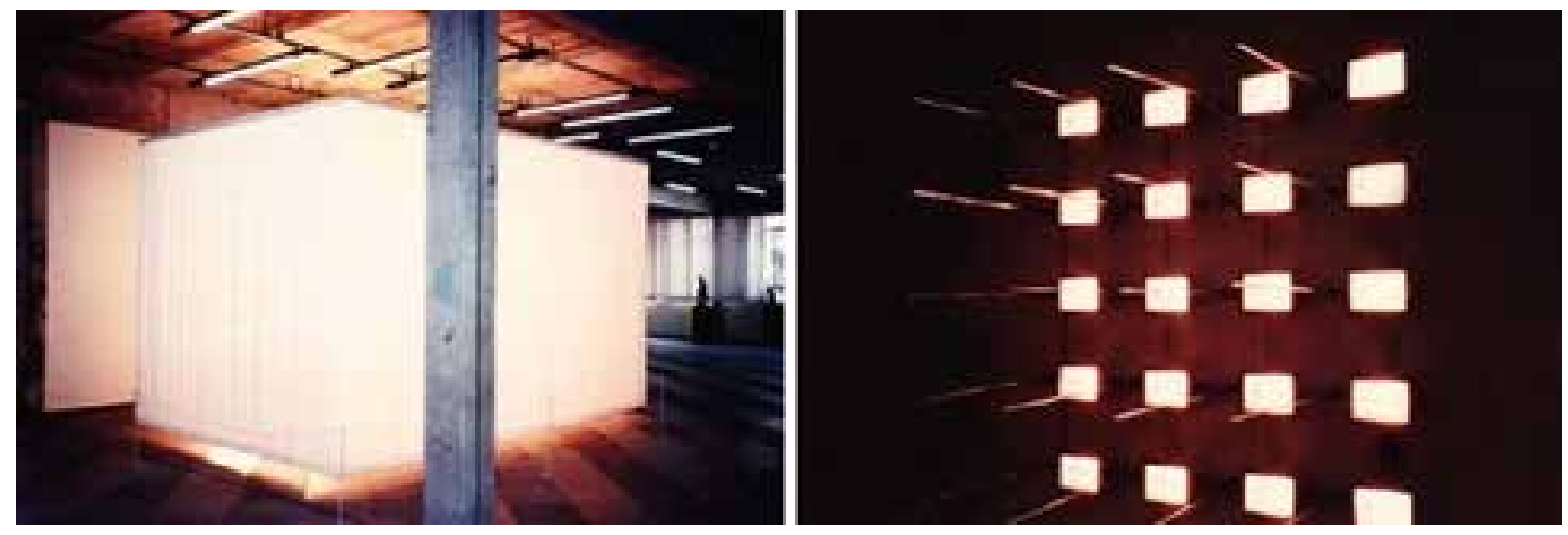

Figura 1 e 2 | Luiz Henrique Schwanke | Paralelepípedo de luz (detalhes) | 1990 | 10 spots de luz de 300 watts, 20 espetos, 33m de cortina de algodão e suporte de ferro $\mid 500 \times 300 \times 500 \mathrm{~cm}^{4}$

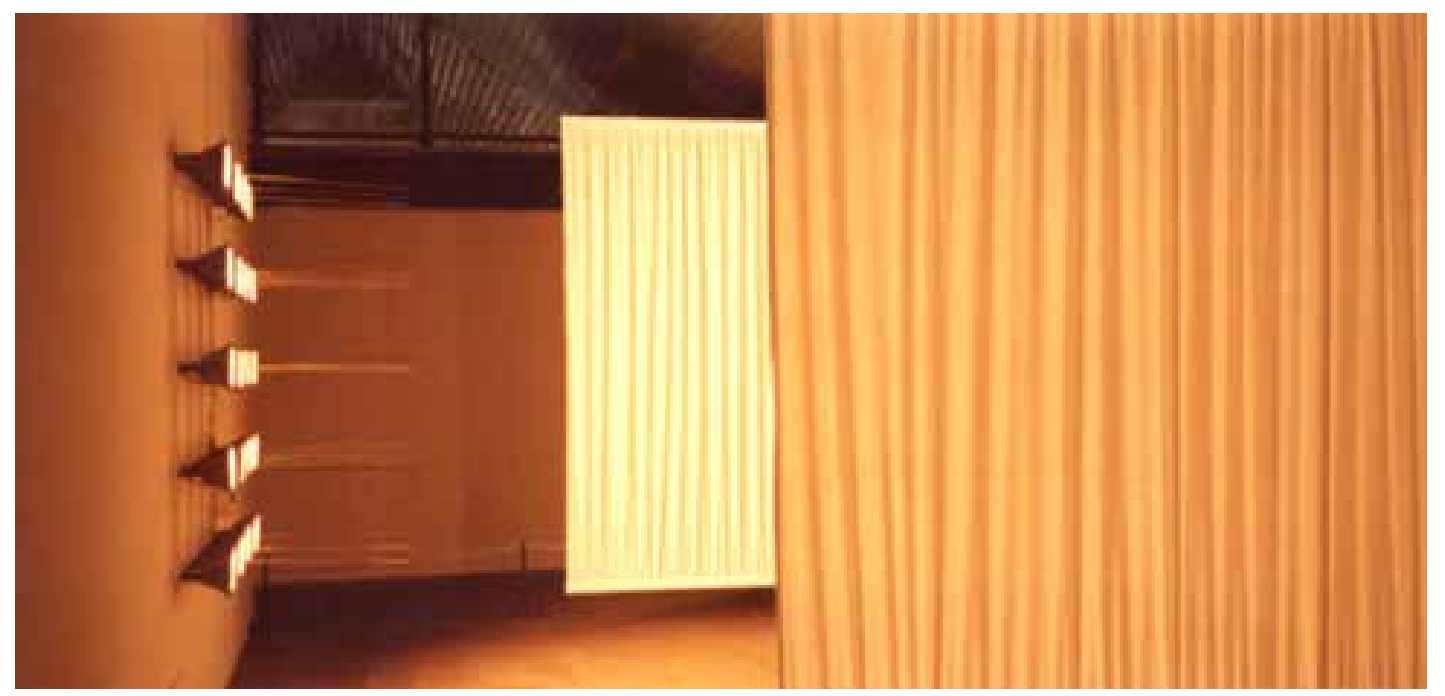

Figura 3 | Luiz Henrique Schwanke | Paralelepípedo de luz | 1990 | 10 spots de luz de 300 watts, 20 espetos, 33m de cortina de algodão e suporte de ferro $|500 \times 300 \times 500 \mathrm{~cm}|$ Detalhe de uma das salas de exposição no Centro Cultural Portão - MUMA - $2001^{5}$

4 Fonte: <http://www.schwanke.org.br/plataformaeducativa/luz/>. Acesso em 14 maio 2016.

5 Fonte: <http://www.schwanke.org.br/plataformaeducativa/luz/>. Acesso em: 14 maio 2016. 
A obra Paralelepípedo de luz ${ }^{6}$ (Figura 3) é constituída por "uma parede de luz formada por vinte refletores de 300 watts cada, intercalados por espetos de churrasco, sustentados por uma estrutura de ferro" (JAHN; LAMAS, 2013, p. 143). Em seu conjunto, os refletores provocam o ofuscamento momentâneo da vista e, com ele, a perda de noções ocasionadas pelos sentidos imediatos, como a distância, por exemplo. Segundo ele, no documentário À luz de Schwanke, nas obras em que a luz podia ser vivenciada diretamente, ele buscava instigar sentimentos de insegurança, uma vez que o artifício proximidade/distância se alterava, tal como em algumas obras da op art. Por fim, Schwanke resolveu "aprisionar toda aquela luz com três paredes de tecido [quase transparentes] na revelação de um volume, o qual, devido ao formato, apelidou de paralelepípedo" (JAHN; LAMAS, 2013, p. 144). A luz, assim, deixava de ser percebida como uma iluminação, adquirindo forma e volume. Da obra mencionada ele chegou ao Cubo de luz (Figura 4) montado uma única vez para 21a Bienal Internacional de São Paulo - que alude à obra Cubocor (1960), de Aloísio Carvão, considerada, por ele, como uma obra fundamental da arte brasileira. O Cubo de luz é composto por um cubo de três metros quadrados, "integrado por quarenta e cinco lâmpadas de 2 mil Watts de multivapores metálicos voltadas para dentro, na projeção de noventa mil watts de luz" (JAHN; LAMAS, 2013, p. 144).

Como o artista descreveu no documentário, o cubo é um objeto mais ligado ao sentido e, por esse motivo, ele tenta construir uma escultura imaterial, sobre o aspecto tátil, já que alguém poderia estar em seu interior. "Ao mesmo tempo em que ela é imaterial, ela é visível, porque as pessoas podem ver, e sendo visível, ela é incontemplável, porque no seu interior nenhuma pessoa poderia ficar contemplando essa grande quantidade de luz que existe lá dentro"7. E concluiu que seu ideal utópico era arquitetar um cubo com a maior concentração possível de luz. A partir da perspectiva de uma escultura imaterial que acarreta o ofuscamento da visão e a perda de determinadas percepções culturais, é possível construir uma associação com outra questão identificada em Bataille: o informe. Porém, no caso de Schwanke, ele estaria presente às avessas, isto é, se o informe é aquilo que o dispositivo ocular apenas reconhece a partir de uma breve aproximação com algo já conhecido, na obra Cubo de luz, o informe ocasiona a perda de qualquer noção prévia de conhecimento retido na memória, desorienta o dispositivo ocular e expõe os demais sentidos do corpo à vulnerabilidade do desconhecido. Portanto, pode-se considerar que os trabalhos nos quais Schwanke utilizou o elemento luz representam o ápice de sua carreira.

6 Obra apresentada no Panorama do Volume, no Museu de Arte de Santa Catarina (MASC), em 1990, em Florianópolis.

7 Documentário À luz de Schwanke. Direção: Ivaldo Brasil Jr. e Mauricio Venturi; Roteiro: Ivaldo Brasil Jr. e Kátia Klock. Joinville: Contraponto, 2008.17 min. Parte em especial: <https://www.youtube.com/watch?v=fTEzlkRZI7w>, com a entrevista concedida à Rede Record em 1991. 


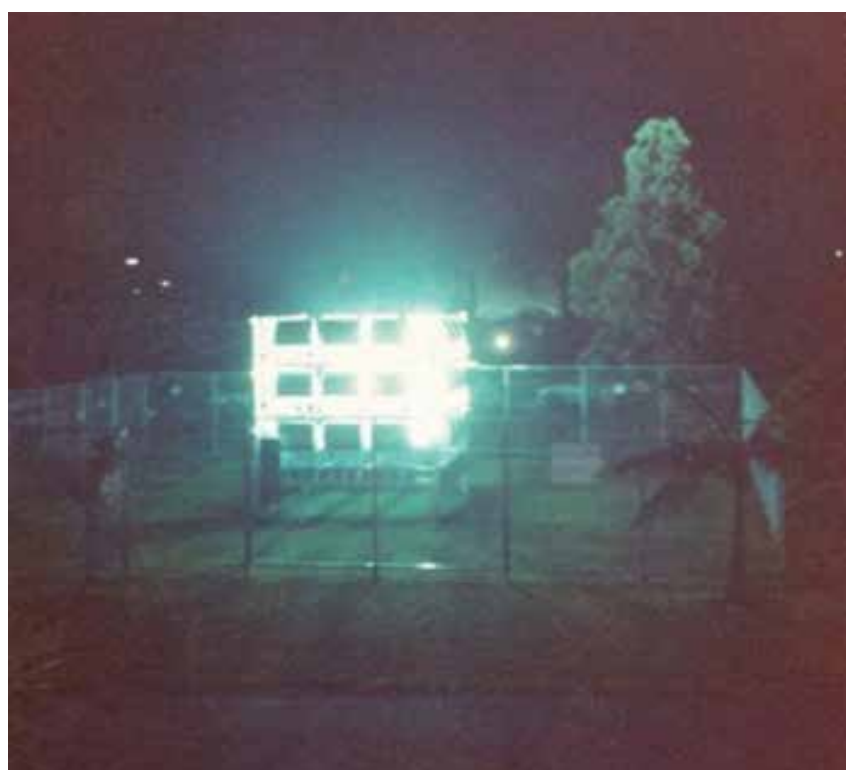

Figura 4 | Luiz Henrique Schwanke | Cubo de luz ou Antinomia | 1991 | Estrutura metálica, 45 lâmpadas de multivador metálico | 3 m² | Instituto Schwanke | Joinville, Brasil ${ }^{8}$

De volta à Bataille e suas indagações referentes ao olho, outra fonte que provavelmente motivou a invocação da cegueira e suas profundas ressonâncias, segundo Martin Jay, foi seu pai cego, que morreu demente em 1916. Entretanto, apesar das especulações a cerca dos motivos que conduziram Bataille ao interesse pelo tema, sua atração pelo dispositivo ocular resultou em seu livro História do olho, no qual nos apresenta a figura do "olho enucleado", ou seja, de um olho incapaz de ver, "uma versão paródica da separação da vista em relação ao corpo, característica da tradição cartesiana" (JAY, 2007, p. 169). "O mais famoso caso de auto enucleação é o de Édipo, personagem da peça de Sófocles 'Édipo Rei', que arrancou seus próprios olhos após saber que havia assassinado seu pai e se casado com sua mãe" (NUCCl; DALGALARRONDO, 2002, p. 80). Outro caso de enucleação, que será descrito mais adiante, é o crime das irmãs Papin. Para Bataille, nenhuma outra imagem expressava melhor sua obsessiva fascinação pela cegueira que a conhecida cena do olho cortado em Um cão andaluz (1928) de Salvador Dalí e Luis Bruñuel. A título de curiosidade, em oposição à metáfora do Sol cegador tratada nas obras de Schwanke, o artista invocou o "Sol putrefato" que funciona como um antídoto tanto ao sol da tradição ocidental dominante quanto à capacidade artística.

Ademais, para Bataille, o olho possuía "diversos significados que entravam em conflito. Em seu ensaio para Documents, escrito em 1929 e intitulado simplesmente 'Olho', explorou diversos exemplos de medos e angústias gerados pela experiência da vigilância ocular" (JAY, 2007, p. 173), como é o caso das implicações sádicas do olhar punitivo. Ele também indagou sobre o denominado "olho pineal", tão importante à filosofia de Descartes, que teve um papel essencial "na transformação da experiência visual proporcionada pelos dois olhos físicos na vista coerente e unificada da mente ou da alma" (JAY, 2007, p. 173) e que, posteriormente, deu ao artista a possibilidade de inventar uma antropologia fantasmática que oporia a glândula pineal ao dos olhos da vista e da visão racional do olho da mente (JAY, 2007, p. 173). Outras contribuições de 
Bataille à ruptura do regime escópico estão embutidas no privilégio dado ao informe, na construção da imagem do homem acéfalo em contraponto ao "olho pineal", que evidenciou a cabeça como símbolo da razão, na valorização do símbolo do labirinto - símbolo predileto de Nietzsche -, no apreço pela obscuridade literária, na iconografia do heterogêneo e na sua crítica contrailustratada da visão. Segundo Martin Jay, no caso do surrealismo, as principais premissas do pensamento ocularcêntrico sobre a cultura ocidental - a razão especulativa e a observação mimética - foram depreciadas, exceto uma delas, a iluminação visionária. O modelo visionário proposto evoca a figura do vidente, questionada como a própria autoimagem dos surrealistas, e faz alusão ao terceiro olho.

No entanto, as inquietações visuais de Bataille também se estenderam a outros surrealistas que encontravam-se perturbados pelas experiências propostas. Sem adentrar na oposição evidente entre os surrealistas André Breton e Georges Bataille ${ }^{9}$ , e centrando-se nos ecos do pensamento antiocularcêntrico de Bataille, é possível esbarrar em conhecidos nomes como, por exemplo, Roger Caillois e André Masson. Outro autor que se uniu às indagações sobre o visual proveniente dos surrealistas e contribuiu para a corrente de pensamento antiocularcêntrico da época, foi Jacques Lacan. Um dos aspectos provenientes dos surrealistas do qual ele se apropriou para desenvolver sua maneira de pensar foi a questão da enucleação que havia sido exaltada por vítimas da opressão social, como pode ser visto no famoso caso das irmãs Papin, Christine e Léa, que, segundo a descrição do crime, retiraram os olhos de sua patroa e da filha enquanto elas ainda estavam vivas.

\section{A experiência do espelho em Lacan e Cildo Meireles}

O episódio das irmãs Papin foi relatado por Lacan em um artigo para o Minotauro, no qual desenvolveu uma associação entre o crime cometido e as lições de obscuridade de Freud, que haviam ganhado mais força na França. No decorrer de seus estudos, Lacan demonstrou interesse pela dimensão visual da paranoia, pelos vínculos entre visão e agressão, pela identificação narcisista com a figura projetada no outro, pelo autocastigo, entre outros, que o levaram a postular o denominado "estádio do espelho", isto é, um estádio universal pelo qual todos os seres humanos passam e que atribui demasiada importância à visão na constituição do eu. Como escreveu Martin Jay,

\footnotetext{
A universalização e normalização do estádio do espelho - sua maior heresia contra a psicanálise convencional, segundo Didier Anzieu - resultou favorecida pelas diversas influências recebidas por Lacan, algumas de tipo propriamente psicológica, outras de signo cultural em sentindo amplo. Entre elas se encontravam estudos científicos sobre o mimetismo em animais, em especial pombos e gafanhotos, e a memorável comparação realizada por Roger Caillois da conduta humana com o comportamento dos insetos nas páginas do Minotaure. Estas obras pareceram alertar Lacan sobre a importância da fusão visual ${ }^{10}$ com o outro mediante o mimetismo morfológico. (JAY, 2007, p. 261)
}

9 "A recusa de Bataille por parte de Breton se tornou pública no Segundo Manifesto do Surrealismo, datado em 1930". (JAY, 2007, p. 178) 10 Roger Caillois denominava essa condição de psicastenia, cuja fusão provocava um declive da força do eu. 
Lacan dedicou-se também à formação precária do eu e sua dissolução - atribuindo a relevância deste na fase infantil, para construir uma explicação viável -, além de se aproximar de alguns experimentos do psicólogo francês Henri Wallon como, por exemplo, os que sugeriam a diferença entre o comportamento de animais e crianças colocados em frente a um espelho, interpretando-os de maneira mais sombria. Com isso, a experiência do espelho foi convertida em um estádio, passando de uma simples descrição para a elaboração de uma premissa. O estádio do espelho apenas alcançou sua formulação definitiva em 1949, afirmando que "entre os seis e os dezoito meses de idade, a criança atinge um sentido compensatório de identidade mediante a identificação com sua imagem em um espelho" (JAY, 2007, p. 262). É necessário esclarecer que a identificação proposta por ele, por meio da imagem especular, estava antes vinculada ao próprio eu do que associada a uma determinação social. E ainda para ressaltar a importância da crítica realizada por Lacan à constituição do eu, Martin Jay recorreu a outro filósofo: Jean-Paul Sartre.

Segundo ele, enquanto Lacan criticava Sartre por desenvolver uma projeção da autossuficiência da consciência, anterior à dialética intersubjetiva do desejo, também o evidenciava através da demolição do eu transcendental criado pelo olhar interiorizado do outro, remetendo ao estádio do espelho como uma representação ilusória ${ }^{11}$ e uma fonte de alienação - a relação de Sartre com esse estado proposto por Lacan pode ser observada através do vínculo entre ele, seu avô e a fotografia. Além disso, tanto Sartre quanto Lacan compartilharam a desconfiança "do eu espacializado criado pelo olhar ratificado, desconfiança que cabe remontar a reavaliação da temporalidade por parte de Bergson e Heidegger" (JAY, 2007, p. 264). Com seus estudos, tornou-se evidente a associação entre a violência paranoica e o desenvolvimento do estádio do espelho no caso das irmãs Papin, pois "o fracasso na superação do estádio do espelho pode levar a uma repetição de sua agressão" (JAY, 2007, p. 264-265), isto é, na fase de projetar-se (identificar-se) no outro e agredi-lo, recupera-se a premissa que paira sobre o auto-castigo. A partir desses conceitos, Lacan denominou três etapas da consciência humana - o Real, o Imaginário e o Simbólico ${ }^{12}$ - as quais não serão aprofundadas nesse texto.

Posteriormente, Lacan retomou o tema da visão quando reuniu à sua análise da psicose o conceito de "escotomização"13 e se apropriou dos termos visível e invisível de Merleau-Ponty, reformulando os em conceitos como "o olho" e "o olhar" (JAY, 2007, p. 269). Lacan também utilizou esquemas como o triângulo - para ilustrar o entrecruzamento quiásmico do olho e do olhar que, em certo momento, resgata a figura do labirinto, proveniente dos surrealistas, para questionar a perspectiva do olho de Deus sobre o mundo e curiosamente ressaltada por Foucault em alguns textos - e o diedro - para aludir ao sujeito repartido, centro de um campo visual conflituoso. Esses conceitos contribuíram para o discurso antiocularcêntrico que se desenvolveu na França, bem como para as indagações de Lacan sobre o entrelaçamento quiásmico do olho e do olhar. Para exemplificar sua teoria, ele recorreu novamente a Roger Caillois e ao estádio do espelho:

11 Lacan defendeu que o eu não era outra coisa que um constructo ilusório. (JAY, 2007, p. 265)

12 Fase na qual seria possível postular o funcionamento linguístico do inconsciente, e não mais percebê-lo apenas como imagem.

13 Escotomização pode designar tanto uma lesão retiniana produzida por um ponto cego visual quanto um processo de depreciação psíquica. Para Lacan, que mais tarde irá diferenciar os termos "escotomização" e "forclusão", a escotomização sugere a produção de um ponto cego quando algo é muito ameaçador para ser visto. 
Caillois havia plantado a questão dos olhos imitados, ocelos, empregados por certos animais para assustar seus predadores ou suas vítimas, os quais alcançavam seu efeito porque se pareciam aos olhos reais [...] a consequência era que o olho real devia compreender-se como cruzado no campo escópico com o olhar de um olho fingido. O exemplo de Caillois resultava "valioso ao assinalar a pré-existência de um dado-a-ver sobre o visto".

[...] Lacan passava a explicar que o problema de permanecer preso no estádio do espelho, um problema que caracterizava o ocularcentrismo filosófico ocidental em seu conjunto, devia-se precisamente ao excessivo papel do olho à custa do reconhecimento do papel do olhar. (JAY, 2007, p. 272)

Ao associar esse termo à experiência da vigília, em que a consciência permanece apenas com olhos semi-fechados, e do sonho, no qual as imagens se mostram ao inconsciente, o essencial pode desvendar-se para alguém que não é capaz de ver. $\mathrm{E}$ ver poderia estar além do dispositivo ocular, vinculado apenas ao ato de olhar? Isso seria possível através da pulsão ver-se vendo que, a priori, está associada a uma noção cartesiana do sujeito ${ }^{14}$ Talvez sejam perguntas que separam o olho físico do olho da mente e que ainda demorar-se-ão para desvendar o universo peculiar da formação e interpretação de imagens na consciência - e, porque não, no inconsciente também. É pertinente citar que Lacan discordava da afirmação de Sartre de que o olho não podia ver o que o outro olhava. Talvez isso ocorra pela concepção do olhar não estar sempre "fora", mas também pertencer a um "dentro", até mesmo a um "entre".

Mas pode-se considerar que a autêntica reciprocidade do olhar, tanto externo quanto interno, é apenas um ato ilusório que deixa lacunas para que os pontos cegos da constituição do eu consigam formar sua própria imagem. Sujeito de um campo visual conflituoso ${ }^{15}$, Lacan rememorou a pintura Os Embaixadores (1533), de Hans Holbein (Figura 5), tonando-se tanto o espectador do quadro, quanto sua caveira distorcida. A pintura, segundo Julian Bell, representa dois franceses diante de uma Inglaterra que hesitava entre o catolicismo romano e o protestantismo.

Estadista e eclesiástico, eles ladeiam um globo celestial acima e um globo terrestre abaixo, além de instrumentos astronômicos, matemáticos e artigos politicamente provocantes - um hinário luterano, um tapete otomano, uma corda de alaúde partida. E então, nesse arranjo enciclopédico, um enigma que anula todos os outros enigmas desfere um golpe devastador: uma caveira distorcida por outra inovação recente [...]. (BELL, 2008, p. 204)

\footnotetext{
14 Apesar de não desdobrar os paradoxos visuais e anti visuais dos pensamentos de Foucault nessa pesquisa, cabe aqui acrescentar uma peculiaridade de seus escritos referentes aos sonhos: "Era também errôneo, advertia Foucault, reduzir a imaginação revelada pelos sonhos a meras imagens. Citando em tom aprovatório a crítica de Lacan contra essa falácia, afirmava que os sonhos transcendiam seu conteúdo visual, e que apontavam a uma verdade ontológica que transbordava a experiência sensorial" (JAY, 2007, p. 293). Talvez essa afirmação seja uma resposta ao seu interesse pela análise da imaginação proposta por Bachelard, em que ele começa a se desvencilhar da fenomenologia e evidencia a separação do pensamento francês entre uma filosofia da experiência, do sentido e do sujeito em contraposição a uma filosofia do conhecimento, da racionalidade e do conceito. "Uma das implicações mais importante da tradição da história da ciência era, de fato, a saída da ontologia e o retorno à epistemologia, mas a uma epistemologia despojada de qualquer raiz reflexiva ou especulativa, que vinculara as ideias na mente com seus supostos objetos no 'mundo real'. [...] O que vemos está mediado pela construção cultural de nossa percepção aparentemente natural'. (JAY, 2007, p. 295)

15 É curioso descrever a relação que Lacan propõe do sujeito real enquanto um sujeito descentralizado, "constituído por uma estrutura que não tem nenhum 'centro', exceto no desconhecimento imaginário do 'eu' [...]". (JAY, 2007, p. 285)
} 


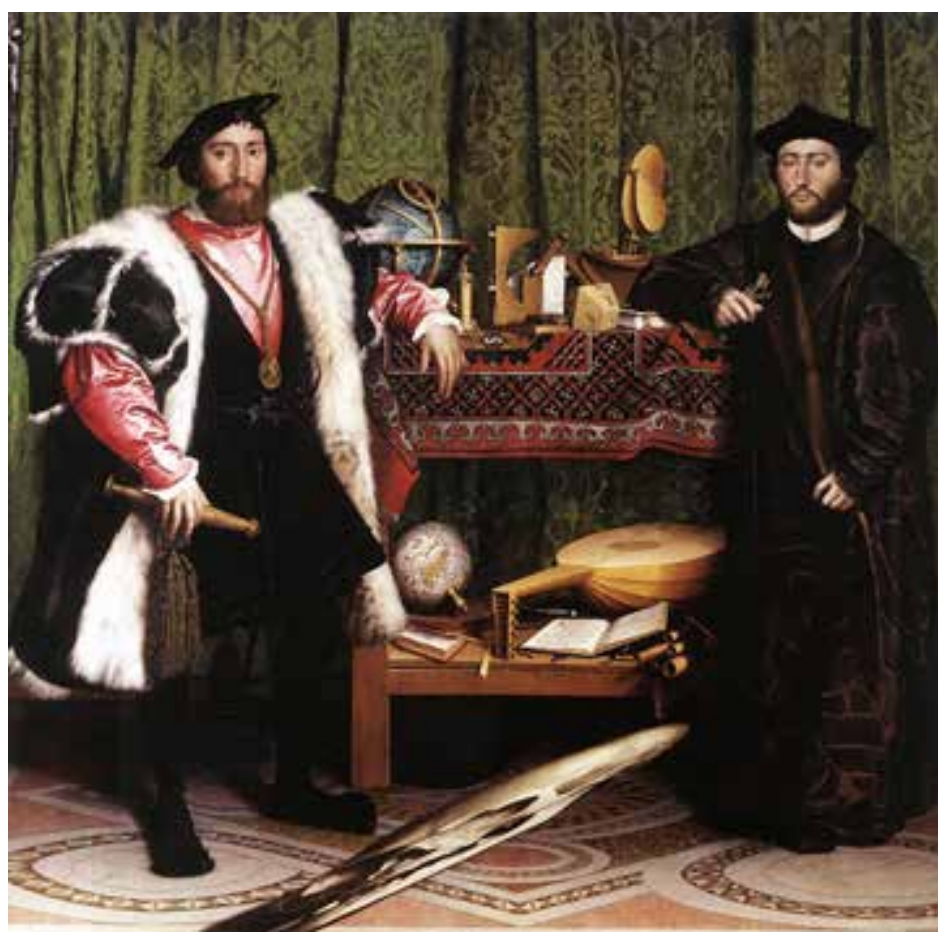

Figura 5 | Hans the Younger Holbein | Os Embaixadores [The Ambassadors] | 1533 | Óleo no carvalho |207x20 cm | Galeria Nacional | Londres, Inglaterra ${ }^{16}$

E, igualmente à dialética negativa de Sartre, Jay a associa com a relação entre pintor e espectador: "nunca me miras desde donde yo te veo [...] lo que miro nunca es lo que quiero ver" (JAY, 2007, p. 278). Assim, uma carência é reportada a tudo aquilo que não se pode ver, ou seja, aquilo que o artista não nos deu para ver, somente para olhar. $O$ vínculo entre pintor/espectador e pintura/linguagem, bem como a relação entre a linguagem e o visível, também estão presentes nas reflexões de Michel Foucault em seu ensaio As Damas de Companhia, no qual ele desenvolve uma leitura imagética da obra de Velásquez. Por fim, Martin Jay aponta outros dois autores que contribuíram para a construção do pensamento antiocularcêntrico na França:

Ainda assim à influência de Lacan, o discurso radical francês dos anos sessenta
se apoiou na crítica do ocularcentrismo. Quase simultaneamente em que se publi-
caram os Écrits, apareceram dois poderosos livros que ressaltaram mais a aposta
contra o privilégio ocidental do visual: As palavras e as coisas, de Michel Fou-
cault, e A sociedade do espetáculo, de Guy Debord. Nestas e outras obras escritas
por estes teóricos e por seus colaboradores nos sessenta e setenta, as implicações
sociais e políticas do ocularcentrismo se examinaram com uma perentoriedade
desconhecida. Agora, o olhar não somente se vinculava aos sonhos psicológicos
do Imaginário e a dialética impessoal do Olhar, mas também remetia às institui-
ções sociais de vigilância e ao espetáculo. O olho maligno emergiu do âmbito
da superstição para converter-se na metáfora dominante do controle social e da
opressão política. (JAY, 2007, p. 286)

Foucault apreciou a importância da visão, porém sua obra apresenta fragmentos em que sua desconfiança torna-se evidente perante a inocência da visão, e demonstra resistência à llustração e à noção ocularcêntrica da Razão como verdade universal. Em uma breve passagem, Jay associa a loucura, a cegueira e a noite ao

16 Fonte: <http://www.wga.hu/index1.html>. Acesso em 13 mar. 2016. 
nascimento do asilo, remetendo à casa dos Quinze-Vingts, instituição que abrigou e apoiou financeiramente os indigentes cegos de Paris ${ }^{17}$.

Para o espírito clássico, a essência da loucura era, ou a cegueira, termo que se referia 'a noite que transcorre entre a vigília e o sonho, a qual rodeia as imagens da loucura $[. .$.$] ou a ofuscação, que significa que 'o louco vê a luz do dia, a mesma$ luz do dia que o homem da razão, mas vendo a luz do dia, e nada mais que essa luz do dia, a vê como vazio, como noite, como nada'. [...] A definição visual da loucura alcançou sua expressão institucional com o nascimento do asilo, onde 'a loucura agora só existe como algo para ver [...]. (JAY, 2007, p. 296)

Posteriormente, Foucault introduziu a noção do "olho falante", isto é, de um olhar individualizante que não mais vê uma realidade objetiva diante de um olho inocente [tão valorizado pela Ilustração e pelo Romantismo], mas sim um campo construído, visual e linguisticamente (JAY, 2007, p. 298). Diferenciou, ainda, o que ele denominou de "visão" e "visão transgressora" e que perpassa o pensamento de Bataille: a primeira representa uma filosofia cartesiana de reflexão ou uma ciência da observação, que busca a transparência e a verdade pura, ao passo que a segunda inverte por completo essa orientação, construindo a imagem de um olho exorbitado, que denigre o sentido da visão e a possibilidade de ver. "Aquele olho sugere, portanto, um vínculo entre a finitude humana, os limites da linguagem, não suscetíveis de superação dialética e a morte de Deus [...]" (JAY, 2007, p. 304). E apesar de a linguagem introduzir as noções de observação psiquiátrica da época, a visão se manteve como o sentido dominante, induzindo, talvez, Foucault a indagar sobre as mudanças de um espectador ausente para um espectador observado, e os níveis de opacidade da linguagem que caracterizaram a ruptura do paradigma humanista.

Ao tratar de novas reflexões a cerca do desenvolvimento humano frente ao espelho, particularmente sobre a construção da própria imagem, é plausível construir um diálogo com a obra Espelho Cego (1970), do carioca Cildo Meireles, considerado um dos artistas que mais se aproxima da cegueira contemporânea, isto é, da cegueira dita funcional. Apesar de Meireles ser considerado um dos pioneiros na construção de ambientes e instalações no Brasil - tendo o país como referência em alguns de seus trabalhos, prevalecendo os aspectos não regionalizáveis, isto é, aspectos que são questões do sujeito (HERKENHOFF, 2001, n.p.) -, seu interesse expande-se também ao âmbito da metáfora, ao contrário do que ocorre com os artistas pós-minimalistas. Segundo o artista, seus trabalhos passam por uma noção de território que, [não somente] naquele momento do país, encontrava-se em estado de indefinição, sendo possível associar essa condição à instabilidade do sujeito, à perda de sua constituição e, com isso, do seu suposto reflexo construído pela sociedade. "Pessoalmente, sempre achei a noção de país - como extensão do corpo ou lugar da felicidade localizada - um código de classificação tão vago e impreciso quanto qualquer outro" (HERKENHOFF, 2001, n.p.). Em outro momento, Cildo Meireles afirma que o malaba-

\footnotetext{
17 Um relato antigo, extraído de arquivos de instituições para cegos em todo o mundo, é apontado no ensaio Cegueira e Cultura Visual: o relato da testemunha ocular de Georgina Kleege. No ensaio, ela menciona um texto escrito em 1825 por Thérèse-Adèle Husson, uma francesa de vinte e dois anos de idade. Husson nasceu em Nancy, numa pequena família burguesa, e ficou cega aos nove meses, depois de um surto de varíola. Como seu caso atraiu a atenção da nobreza local, Husson recebeu patrocínio para ser "educada" no convento, onde foi estimulada a cultivar seus interesses pela literatura e pela música. Já aos vinte anos, ela mudou-se para Paris aspirando seguir uma carreira literária e seu primeiro texto Reflexões sobre a condição moral e física do cego, ecoou como um pedido de ajuda relacionado ao Hôpital des Quinze-Vingts.
} 
rista representa uma síntese do conceito de território ao administrar três objetos num espaço para apenas dois, complementando que "nesse caso, tem que se introduzir o conceito de tempo. Na verdade, o malabarista é aquele que encontra um lugar no tempo" (HERKENHOFF, 2001, n.p.).

Ademais, em muitas de suas obras como, por exemplo, em Entrevendo (1994), o espectador beneficia-se do vínculo entre os sentidos e não confia plenamente na visão para reconhecer a materialização de uma forma invisível (GONÇALVES FILHO, 2009, p. 108-109). A consideração anterior pode ser observada na seguinte descrição de Élida Tessler referente à obra Espelho Cego de Cildo Meireles, "está colocada à questão do olhar pelo tocar, pelo tateamento, pela presença da mão como o olho do cego. Um espelho sem imagem [...] Uma obra que somente os cegos podem realmente ver" (TESSLER, 2001, p. 20-21). É provável que seu apreço pelo sentido do tato seja decorrente da proximidade com a obra de Marcel Duchamp e, particularmente, com a criação do ready made que, após a tentativa de libertar a arte do domínio da mão, incitou novos artistas a libertar a arte do domínio do olho (SOUZA, 1981, p. 34). Por esse motivo, Cildo Meireles buscou "aprofundar incisivamente a contravenção duchampiana" (SOUZA, 1981, p. 34) tratando-a como um pressuposto "à ruptura de Duchamp, já parte dessa transgressão das leis que limitam ou interditam o 'espaço sagrado' da Arte" (SOUZA, 1981, p. 34). Portanto, "o trabalho de Cildo investe de frente, mas não às cegas, contra o domínio do olhar, contra a prioridade mistificadora do Olho" (SOUZA, 1981, p. 34). "Quente-terra-cega" trata-se de uma denominação abrangente aplicada a uma série de projetos desenvolvidos pelo artista ao longo de alguns anos, bem como certas exposições como EUREKA/BLINDHOTLAND, ocorrida no Museu de Arte Moderna do Rio de Janeiro, em 1975, que "consistia em um conjunto de trabalhos em que já se pretendia na verdade criar um 'campo' de neutralização do poder do Olho" (SOUZA, 1981, p. 37), que contaminam a obra tratada a seguir e sintetizam, com suas reflexões posteriores, o pensamento antiocularcêntrico. 


\begin{abstract}
As primeiras anotações, os primeiros projetos relacionados a essa ideia de trabalhar sobre sensações não diretamente subordinadas ao domínio do olho, nasceram em 1970, quando o artista começa a ativar um repertório de manifestações vinculadas a outros níveis sensoriais (a audição, o paladar, o peso), onde já se torna muito claro que a simples percepção visual, a sabedoria do olho, passa a um segundo plano. O olhar por si só, pouco ou nada revela. Nesses trabalhos, a apreensão retiniana deixa de servir como chave única para uma leitura global da obra. O significado desta só se revela ou se totaliza na medida em que pode ser 'lido' em novas áreas de percepção sensorial. (SOUZA, 1981, p. 34)
\end{abstract}

A linha de pensamento da citação anterior pode ser estendida à compreensão da obra Espelho Cego (Figura 6). Essa obra é constituída por um espelho comum de hospital, cujo vidro foi substituído por uma espécie de borracha mole (massa de calafate) com as informações verbais de praxe em relevo, tal como no Braille, e especularmente invertidas (SOUZA, 1981, p. 33). Ao subverter a função habitual do espelho, remetendo-a apenas por meio da linguagem, Cildo tinha por objetivo produzir uma imagem tátil do objeto. Considerado um dos primeiros projetos da série BLINDHOTLAND, o intuito era criar "trabalhos plásticos que pudessem ser fruídos por cegos, sem perda substancial de significado" (SOUZA, 1981, p. 33). De acordo com Jaime Ginzburg,

Ao observar a peça, o espectador é confrontado com uma massa que, de modo ambivalente, está entre a forma e o informe. Acostumados com a ideia de que um espelho devolva nossa imagem tal como é, vivemos situação similar à do protagonista do conto $\mathrm{O}$ espelho, de Guimarães Rosa. [...] A obra não apenas sugere que o espelho seja cego por ser incapaz de retribuir como esperado pela retina.

É a própria visão do espectador que, pela vivência do choque, se vê ameaçada por uma contemplação que provoca tensão na estabilidade do olhar. [...] O espectador, se sustentar o olhar, se perguntará pelos limites da própria percepção, limites que estabelecem uma impossibilidade de deixar fluir a visão. O que está sendo visto, o que pode ser visto? [...] É a própria visão do espectador que percebe seu limite, sua incapacidade de ver. [...] É um sujeito que, descobrindo uma distância entre sua auto-imagem habitual e inesperadas imprecisões, está aquém de si mesmo". (GINZBURG, 2004, p. 89-90)

Enquanto metáfora, "a obra de Meireles articula uma moldura, produzida industrialmente, com a textura cinzenta cadavérica [pois] o Brasil em que a obra de Meireles surge é o país da ditadura opressora, que retifica e mata por princípio [...]" (GINZBURG, 2004, p. 90). Ao analisar a obra e ao considerar particularidades da entrevista presente no artigo Filho de Marx e da Coca-Cola ou o curto-circuito da arte, publicado em 21 de julho de 2000, conclui-se que Cildo Meireles não buscou aleatoriamente uma síntese visual, isto é, uma limpeza formal, pois acreditava que sua produção política, cedo ou tarde, se justificaria por parâmetros artísticos. Prova disso, é a moldura retangular que aponta para a exigência contemporânea de enquadramento racional. Essa moldura, adequada às necessidades industriais, contorna a experiência do monstruoso. Semelhante às usadas em espelhos, ela aponta para a necessidade de acomodar a experiência humana em enquadramentos pré-definidos (GINZBURG, 2004, p. 90).

Interligando os rastros deixados por Meireles, é possível encontrar 
na cegueira uma forma particularmente importante de expressão da tragicidade moderna. Em tempos de catástrofes e desumanização, artistas e escritores procuram formas que, de algum modo, estejam ligadas a uma experiência fragmentária e delicada de constituição de sujeito. (GINZBURG, 2004, p. 91)

Como espectador de uma experiência-limite, na Figura 6,

olhamos para o espelho cego e o que vemos é desarticulado, monstruoso, oscilante entre o inteligível e o inefável. Movemos o rosto para o lado, para a parede, a rua, e o limite cognitivo e epistemológico se mantêm. Como dizia Benjamin dos experimentos do surrealismo, o cotidiano se torna impenetrável. (GINZBURG, 2004, p. 93)

Assim, ao indagar sobre o limiar interior/exterior e subverter a função do espelho, colocando à prova o regime escópico, isto é, o regime que situa a experiência visual em primeiro plano, Cildo Meireles cria um ponto cego na hierarquia dos sentidos e rompe com o código vigente da arte.

Mais uma vez, a discussão acerca da cegueira, por artistas como Cildo Meireles e Luis Henrique Schwanke, propõe um questionamento aos videntes ao associar o aparato da visão a sua capacidade de impossibilitá-la. Com isso, paradoxos proporcionados pela luz e pelo espelho suscitam novamente as ilusões acarretadas pelo dispositivo ocular. Neste ponto, a cegueira funcional é tratada com o mesmo zelo com que os próprios intelectuais abordaram o pensamento antiocularcêntrico, ou seja, considerando as ambiguidades referentes à polaridade visão e cegueira e apoiando-se em cada uma para desdobrar o seu avesso, acabam por demonstrar que o próprio excesso de uma é a causa principal da outra. Dito isto, este texto pode ser considerado como uma transição entre o pensamento vigente na consolidação do regime escópico e sua posterior desvalorização por parte de determinados autores e artistas que evidenciaram suas inquietudes visuais. Entretanto, é possível observar que, embora a corrente ocularcêntrica tenha se tornado alvo de críticas ao longo da história e tenha perdido um pouco da sua intensidade, a primazia concedida à visão ainda é preponderante na contemporaneidade.

Por esse motivo, a cegueira funcional é um tema recorrente nos dias de hoje devido à grande quantidade de imagens que não somente perturba a construção de uma história, mas também desconstrói e oblitera a concepção da imagem própria de cada indivíduo. A contemporaneidade é constituída por uma visualidade poluída e uma ideia de imediatismo que não se sabe ao certo o quanto prejudica a recepção da figura por meio do dispositivo ocular e sua posterior interpretação. E, embora a pesquisa não desconsidere a importância da visão para as Artes Visuais enquanto almeja desconstruir sua hegemonia acima dos demais sentidos e problematizar uma formação de imagens que utilize, em sua construção, o vínculo entre dois ou mais sentidos, talvez seja o momento de desconfiar do visível e conceder aos demais sentidos a percepção e a recepção de tudo aquilo que é exterior ao sujeito. Por vezes, ainda, dever-se-ia tomar o mesmo cuidado com que Foucault analisou a pintura de Velásquez em As Damas de Companhia: "é preciso então fingir não saber quem se refletirá no fundo do espelho e interrogar esse reflexo no próprio nível de sua existência" (FOUCAULT, 2009, p. 202). 


\section{Referências Bibliográficas}

BAHIA, L. H. F. Cegueira e Artes Visuais: paradoxos e implicações. Dissertação (Mestrado) - Universidade do Estado de Santa Catarina, Centro de Artes, Programa de Pós-Graduação em Artes, Florianópolis, 2016.

BATAILLE, G. História do olho. Tradução de Eliane Robert Moraes. São Paulo: Cosac \& Naify, 2003.

BELL, J. Uma nova história da arte. Tradução de Roger Maioli. São Paulo: Editora Martins Fontes, 2008.

BORGES, A. C.. Georges Bataille: imagens do êxtase. Fevereiro, no 9, n.p. Fortaleza São Paulo: Agulha, Revista de Cultura, 2001. Disponível em: <http://www.jornaldepoesia.jor.br/ag9bataille.htm>. Acesso em: 14 maio 2016.

FONTCUBERTA, J. A câmera de Pandora: a fotografi@a depois da fotografia. Tradução de Maria Alzira Brum. São Paulo: Editora G. Gilli, 2012.

FOUCAULT, M. A Arqueologia do saber. Tradução de Luiz Felipe Baeta Neves. $7^{a}$ edição. Rio de Janeiro: Forense Universitária, 2008.

As palavras e as coisas: uma arqueologia das ciências humanas. Tradução de Salma Tannus Muchail. 8ª edição. São Paulo: Martins Fontes, 1999. (Coleção tópicos).

Estética: literatura e pintura, música e cinema. Organização de Manoel Barros de Motta e tradução de Inês Autran Dourado Barbosa. 2ª edição, Ditos e Escritos, Volume III. Rio de Janeiro: Forense Universitária, 2009.

GINZBURG, Jaime. Cegueira e literatura. In: VECCHI, Roberto; FINAZZI-AGRÒ, Ettore. Formas e mediações do trágico moderno: uma leitura do Brasil. 1a edição, volume II, cap. 1.6, p. 89-98. São Paulo: Unimarco Editora, 2004.

GONÇALVES FILHO, A. Primeira individual: 25 anos de crítica de arte. São Paulo: Cosac Naify, 2009.

HERKENHOFF, P. Cildo Meireles, geografia do Brasil. Rio de Janeiro: Artviva Produção Cultural, 2001.

JAHN, A. R. M.; LAMAS, N. de C. O ecossistema poético de Luiz Henrique Schwanke. 22을 Encontro Nacional Anpap, Outubro, p. 132-147. Belém: Anais Anpap, 2013. Disponível em: <http://www.anpap.org.br/anais/2013/ANAIS/comites/htca/Alena\%20 Rizi\%20MArmo\%20Jahn\%20e\%20Nadja\%20de\%20Carvalho\%20Lamas.pdf>. Acesso em: 18 maio 2016. 
JAY, M. Ojos Abatidos: la denigración de la visión en el pensamiento francés del siglo XX. Tradução de Francisco López Martín. Madri, Espanha: Editora Akal, S.A., 2007. Tradução nossa.

KLEEGE, G. Blindness and Visual Culture: An Eyewitness Account. In: DAVIS, Lennard J.. The Disability Studies Reader. 4ª edição, cap. 32, p. 447-455. New York: Routledge, 2013. Tradução nossa.

LAMAS, N. de C.. Revisitamento "na" e "da" obra de Schwanke. Tese em Artes Visuais; orientadora Doutora Icleia Borsa Cattani. Porto Alegre: UFRGS, 2005.

NUCCI, M. G.; DALGALARRONDO, P. Automutilação ocular: relato de seis casos de enucleação ocular. Junho, vol. 22, n 2, p. 80-86. São Paulo: Revista Brasileira de Psiquiatria, 2002. Disponível em: <http://www.scielo.br/scielo.php?script=sci_arttext\&pid=S1516-44462000000200009>. Acesso em: 18 maio 2016.

SACKS, O. O olhar da mente. Tradução de Laura Teixeira Motta. São Paulo: Companhia das Letras, 2010.

SARAMAGO, J. Ensaio sobre a cegueira. São Paulo: Companhia das Letras, 1996.

SAINT-EXUPÉRY, A. de. O Pequeno Príncipe. Tradução de Frei Betto. São Paulo: Geração Editorial, 2015.

SOUZA, E. A. M. de. Blindhotland. In: MEIRELES, Cildo. Cildo Meireles. 1ª edição, cap. 1, p. 30-37. Rio de Janeiro: FUNARTE, 1981.

SOUZA, J. P. de. Teorias da Tradução: uma visão integrada. Janeiro/Dezembro, vol. 1/2, n 20, p. 51-67. Revista de Letras, 1998. Disponível em: <http://www.revistadeletras.ufc.br/rl20Art09.pdf>. Acesso em: 21 agosto 2015.

TESSLER, Élida. Cegos conduzindo Cegos: algumas parábolas e outras incontinências do visual. Porto Alegre: Catálogo MARGS, 2001. 23 de agosto a 30 de setembro.

Vários autores. Arte Contemporânea: salão Luiz Henrique Schwanke. Jaraguá do Sul: Sociedade Cultura Artística, 2002.

Documentário. À luz de Schwanke. Direção: Ivaldo Brasil Jr. e Mauricio Venturi; Roteiro: Ivaldo Brasil Jr. e Kátia Klock. Joinville: Contraponto, 2008. 17 min. Parte em especial: <https://www.youtube.com/watch?v=fTEzlkRZI7w>. Acesso em: 18 maio 2016. 